\section{Uso recomendado de antirretrovíricos en embarazadas infectadas por el VIH-1 para reducir la transmisión perinatal del virus ${ }^{1}$}

Palabras clave: VIH-1, transmisión perinatal, antirretrovíricos, prevención, cesárea.

\footnotetext{
Basado en la revisión del 4 de mayo de 2001 del documento "Public Health Service Task Force Recommendations for Use of Antiretroviral Drugs in Pregnant HIV-1-Infected Women for Maternal Health and Interventions to Reduce Perinatal HIV-1 Transmisión in the United States", elaborado por el Perinatal HIV Guidelines Working Group y publicado inicialmente el 24 de enero de 20001 Disponible en: http://www.hivatis.org/guidelines/perinatal/May03_01/PerinatalMay04_01.pdf . Acceso el 24 de mayo de 2001.
}

En febrero de 1994, un ensayo clínico del Pediatric AIDS Clinical Trials Group (PACTG 076) demostró por primera vez la posibilidad de reducir en cerca de un $70 \%$ el riesgo de transmisión vertical del virus de la inmunodeficiencia humana de tipo 1 (VIH-1) mediante la administración de un régimen terapéutico con tres componentes: 1) zidovudina (ZDV) oral desde las 14 a 34 semanas de gestación hasta el final del embarazo; 2) ZDV intravenosa (i.v.) durante el parto, y 3) administración de ZDV oral al recién nacido durante las primeras 6 semanas de vida. Posteriormente, estudios epidemiológicos realizados en los Estados Unidos de América (EE.UU.) y Francia demostraron que este régimen proporcionaba una reducción drástica de la transmisión perinatal en la práctica clínica. Desde entonces se han producido importantes adelantos, no solo terapéuticos (nuevos fármacos y regímenes terapéuticos muy eficaces) y diagnósticos (pruebas que permiten cuantificar la carga vírica), sino también en la comprensión de la patogenia de la transmisión perinatal del VIH-1.

Este informe proporciona: a) una revisión de las consideraciones especiales que hay que tener en cuenta al utilizar antirretrovíricos en embarazadas; b) una actualización de los resultados de los estudios clínicos y epidemiológicos sobre la prevención de la transmisión perinatal del VIH-1; c) un análisis del uso de las pruebas de cuantificación del ARN del VIH-1 (carga vírica) durante el embarazo, y d) una actualización de las recomendaciones sobre el empleo de la quimioprofilaxis antirretrovírica y de la cesárea electiva para reducir la transmisión perinatal del virus. Estas recomendaciones están destinadas a los EE.UU. y es posible que en otros países sean preferibles estrategias distintas.

\section{ANTECEDENTES}

Consideraciones relacionadas con el uso de antirretrovíricos en embarazadas infectadas por el VIH-1 y sus hijos

Las recomendaciones terapéuticas para embarazadas infectadas por el VIH-1 han partido del principio de que no se deben suspender durante el embarazo tratamientos beneficiosos para la mujer, 
a no ser que tengan efectos adversos maternos, fetales o neonatales que superen los beneficios para la mujer. En adultos no gestantes actualmente se recomienda el tratamiento antirretrovírico (TAR) combinado, generalmente consistente en dos inhibidores de la transcriptasa inversa análogos de los nucleósidos y un inhibidor de la proteasa. El embarazo no debería impedir el uso de regímenes terapéuticos óptimos. No obstante, al elegir los antirretrovíricos en embarazadas hay que tener en cuenta aspectos especiales como: a) la necesidad de efectuar ajustes de las dosis condicionados por los cambios fisiológicos que se producen en el embarazo; b) los potenciales efectos de los antirretrovíricos en la embarazada, y c) los potenciales efectos a corto y a largo plazo de los antirretrovíricos sobre el feto y el recién nacido. La decisión de usar cualquier antirretrovírico durante el embarazo debe ser tomada por la mujer después de comentar con su médico los beneficios y riesgos, tanto conocidos como desconocidos. Los potenciales riesgos para el feto dependen del fármaco, de la dosis, de la edad gestacional en el momento de la exposición, de la duración de esta, de las interacciones con otros fármacos y de las características genéticas de la madre y del feto. Los datos acerca de la farmacocinética y la seguridad de los antirretrovíricos durante el embarazo son mínimos, excepto en el caso de la ZDV.

\section{TAR combinado y desenlace del embarazo}

Los datos sobre el TAR combinado en el embarazo son escasos. Los resultados preliminares de un metaanálisis de múltiples ensayos clínicos perinatales y estudios epidemiológicos no muestran un aumento del riesgo de parto pretérmino en comparación con la monoterapia o la ausencia de TAR. Mientras no haya más información, se recomienda que las embarazadas infectadas por el VIH-1 sigan con su tratamiento habitual y sean vigiladas periódicamente en busca de complicaciones del embarazo y potenciales efectos tóxicos.

\section{Tratamiento con inhibidores de la proteasa e hiperglucemia}

Los inhibidores de la proteasa se han asociado a hiperglucemia, aparición de diabetes o agravación de la diabetes ya existente y cetoacidosis diabética. Además, el embarazo constituye en sí mismo un factor de riesgo de hiperglucemia. Por consiguiente, las embarazadas tratadas con inhibidores de la proteasa requieren un cuidadoso control de la glucemia.

\section{Toxicidad mitocondrial y análogos de los nucleósidos}

Los análogos de los nucleósidos producen disfunción mitocondrial, debido a su afinidad por la ADN-polimerasa gamma mitocondrial. En este aspecto, el orden de potencia de los análogos de los nucleósidos es el siguiente: zalcitabina $>$ didanosina $>$ estavudina $>$ lamivudina $>$ ZDV $>$ abacavir. La toxicidad relacionada con la disfunción mitocondrial suele resolverse con la interrupción del tratamiento y posiblemente esté relacionada con una susceptibilidad genética.

Problemas en el embarazo. Los trastornos relacionados con la toxicidad mitocondrial incluyen la neuropatía, miopatía, miocardiopatía, pancreatitis, esteatosis hepática y acidosis láctica. Estos dos últimos trastornos predominan en las mujeres y podrían estar relacionados con la esteatosis hepática aguda del embarazo y el síndrome HELLP (hemólisis, elevación de las enzimas hepáticas y trombocitopenia). La acidosis láctica con esteatosis hepática microvacuolar se describió inicialmente con la ZDV, pero posteriormente se ha observado con otros análogos de los nucleósidos, en particular con la estavudina. Se desconoce la frecuencia de este síndrome en embarazadas tratadas con análogos de los nucleósidos y no se sabe si el embarazo aumenta su incidencia. No obstante, se recomienda determinar frecuentemente las concentraciones de enzimas hepáticas y electrólitos durante el tercer trimestre del embarazo. Además, como se han descrito varias muertes maternas por acidosis láctica en casos tratados durante largo tiempo con estavudina y didanosina, esta combinación solo se debería prescribir cuando hayan fracasado otras combinaciones de análogos de los nucleósidos.

Problemas de la exposición in utero. Se han descrito ocho casos de niños no infectados expuestos in utero o durante el período neonatal a la ZDV o a la combinación de ZDV y lamivudina que presentaron signos de disfunción mitocondrial tras los primeros meses de vida. Dos de ellos, con trastornos neurológicos graves, fallecieron; otros tres presentaron síntomas leves a moderados, y los tres restantes, asintomáticos, solo presentaron alteraciones de las pruebas de laboratorio. No obstante, no se ha establecido todavía una asociación entre estas alteraciones y la exposición in utero a los antirretrovíricos. Aunque se demostrara dicha asociación, la aparición de enfermedades mitocondriales graves o letales en estos lactantes parece ser extremadamente 
rara y tendría que ser comparada con el claro beneficio aportado por los antirretrovíricos en lo que se refiere a la reducción de la transmisión perinatal del virus.

\section{Registro de Antirretrovíricos en el Embarazo}

Este registro es un proyecto epidemiológico de recogida de datos observacionales, no experimentales, sobre la exposición a los antirretrovíricos durante el embarazo, con el fin de evaluar su potencial teratogenicidad. Se encarece a todos los médicos que estén tratando a embarazadas infectadas por el VIH-1 y a sus hijos que notifiquen a este registro los casos de exposición prenatal a los antirretrovíricos.

\section{Actualización sobre los estudios relacionados con la quimioprofilaxis con ZDV de la transmisión perinatal del VIH-1}

En 1996 se publicaron los resultados finales del ensayo clínico PACTG 076, que confirmaron los resultados preliminares descritos en 1994; la tasa de transmisión fue del $22,6 \%$ en el grupo tratado con placebo, frente al 7,6\% en el tratado con ZDV, lo cual representa una reducción del $66 \%$. Dicha eficacia se ha confirmado también en poblaciones diferentes de la del estudio PACTG 076, concretamente en mujeres con enfermedad avanzada y recuentos bajos de linfocitos CD4+ expuestas anteriormente a la ZDV. Los mecanismos mediante los cuales la ZDV reduce la transmisión todavía no están totalmente esclarecidos. El efecto de la ZDV sobre la carga vírica materna no explica totalmente la reducción de la transmisión vertical. Por otra parte, la presencia de virus resistentes a la ZDV no se asocia necesariamente al fracaso de la prevención de la transmisión. Todavía no se conoce el efecto que sobre la inducción de resistencia a la ZDV pueda tener la administración temporal de ZDV durante el embarazo con el fin de reducir la transmisión perinatal.

En el estudio PACTG 076, las tasas de malformaciones congénitas fueron similares en los lactantes expuestos y no expuestos in utero a la ZDV. Además, los datos del Registro de Antirretrovíricos en el Embarazo no han demostrado un aumento del riesgo de malformaciones congénitas en los lactantes expuestos a la ZDV, en comparación con la población general. Aunque en los niños expuestos no se han observado cánceres a corto plazo (hasta los 6 años de edad), la duración del seguimiento es todavía demasiado breve para permitir una evaluación definitiva del riesgo de carcinogénesis.

\section{Ensayos clínicos internacionales sobre la profilaxis antirretrovírica}

En un estudio realizado en Tailandia se ha observado que el tratamiento con ZDV oral durante tan solo 4 semanas antes del parto y durante el parto reduce la transmisión perinatal en aproximadamente un $50 \%$, en comparación con el placebo. Resultados similares se han obtenido en un estudio realizado en África en el que se administró por vía oral la combinación de ZDV y lamivudina desde las 36 semanas de gestación, durante el parto y durante la semana siguiente. También se han identificado dos regímenes intraparto/posparto (ZDV/lamivudina o nevirapina) que podrían ser eficaces en mujeres cuyo diagnóstico de infección por VIH solo se establece durante el parto, o muy cerca del mismo. No hay estudios sobre la profilaxis exclusivamente después del parto. Aunque algunos datos epidemiológicos no respaldan la eficacia de la ZDV administrada únicamente después del parto, otros datos indican que se puede obtener alguna eficacia si el fármaco se empieza a administrar en el primer día de vida. A favor de esta posibilidad se encuentran también los resultados de un estudio de casos y controles de trabajadores sanitarios expuestos a sangre contaminada, en los que el tratamiento con ZDV tras la exposición redujo la probabilidad de contraer la enfermedad.

\section{Carga vírica materna y transmisión perinatal del VIH-1}

La correlación entre la carga vírica y el riesgo de progresión de la enfermedad en adultos no gestantes indica que la carga vírica debería ser determinada durante el embarazo al menos con la misma frecuencia que en no gestantes, esto es, aproximadamente cada 3 meses. Aunque no hay datos que indiquen que el embarazo acelere la progresión de la enfermedad, no está claro si durante la gestación es necesario aumentar la frecuencia de estas determinaciones. La carga vírica posee escaso valor predictivo con respecto a la transmisión perinatal en casos individuales y en el estudio PACTG 076 la ZDV redujo la transmisión independientemente de la carga vírica materna. No obstante, los datos más recientes indican que la carga vírica está correlacionada con el riesgo de transmisión, incluso en mujeres tratadas con antirretrovíricos. Por otro lado, en algunos casos se ha descrito una discordancia entre la carga vírica en el plasma y en las secreciones genitales. Por consiguiente, si, como se cree, la exposición al VIH en el canal del parto constituye un factor de riesgo de transmisión perinatal, es posible 
que la carga vírica plasmática no siempre constituya un buen indicador del riesgo. La recomendación es ofrecer la posibilidad de recibir quimioprofilaxis para reducir la transmisión perinatal a toda embarazada infectada, independientemente de su carga vírica.

\section{ASESORAMIENTO Y ATENCIÓN PRECONCEPTIVA A LAS MUJERES EN EDAD FÉRTIL INFECTADAS POR EL VIH}

En general, el objetivo de la atención preconceptiva consiste en identificar factores de riesgo de desenlaces adversos maternos o fetales, como la edad, la diabetes o la hipertensión, proporcionar educación sanitaria y asesoramiento, y tratar o estabilizar posibles enfermedades antes de la concepción, con el fin de optimizar los desenlaces maternos y fetales. En mujeres infectadas por el VIH, se recomienda que la atención preconceptiva incluya los siguientes componentes:

- Selección de métodos anticonceptivos eficaces y apropiados para reducir la probabilidad de embarazo no deseado.

- Educación y asesoramiento sobre el riesgo de transmisión perinatal, las estrategias para reducirlo y los potenciales efectos del VIH o del tratamiento sobre el curso del embarazo y su desenlace.

- Comienzo o modificación del TAR antes de la concepción con el fin de:

- Evitar agentes con potencial toxicidad reproductiva para el feto en desarrollo, como el efavirenz o la hidroxiurea.

- Elegir agentes eficaces para reducir el riesgo de transmisión perinatal.

- Alcanzar una supresión máxima y estable de la carga vírica materna.

- Evaluar y controlar los efectos colaterales que puedan afectar a los desenlaces maternofetales (hiperglucemia, anemia, toxicidad hepática)

- Estudio de posibles infecciones oportunistas, inicio de la profilaxis de las mismas y administración de vacunaciones (gripe, neumococos, hepatitis B) en caso de que estén indicadas.

- Optimización del estado nutricional.

- Instauración de medidas preconceptivas habituales, como la detección de enfermedades de transmisión sexual o la administración de suplementos de ácido fólico.

- Detección de posibles trastornos psicológicos y drogadicciones.

- Planificación de consultas perinatales.

\section{PRINCIPIOS GENERALES SOBRE EL USO DE ANTIRRETROVÍRICOS EN EL EMBARAZO}

La atención médica a la embarazada infectada por el VIH-1 requiere coordinación entre su médico habitual y el ginecólogo. El examen inicial de la paciente debe incluir: a) una evaluación del grado de inmunodeficiencia, determinado por el recuento de linfocitos $\mathrm{CD} 4+$; b) el riesgo de progresión de la enfermedad, determinado por la carga vírica plasmática, c) los TAR actuales o pasados; d) la edad gestacional, y e) el apoyo necesario. Las decisiones con respecto a la necesidad de iniciar el tratamiento o de modificarlo deben ser las mismas que en mujeres no gestantes, pero teniendo en cuenta su potencial impacto sobre el feto y el recién nacido.

Las decisiones acerca del uso y la elección de los antirretrovíricos durante el embarazo son complejas. Antes de tomar una decisión, la mujer debe ser informada de: a) lo que se sabe y lo que se desconoce acerca de los efectos de estos fármacos sobre el feto y el recién nacido; b) lo recomendable en el tratamiento de la mujer infectada por VIH-1, y c) la eficacia de la ZDV en la reducción de la transmisión perinatal del VIH. La decisión final sobre el empleo de fármacos antirretrovíricos es responsabilidad de la mujer y el rechazo del tratamiento no debe dar lugar a acciones punitivas ni a la denegación de atención. Una vez tomada la decisión de recibir tratamiento, se debe elaborar un plan terapéutico a largo plazo y hay que subrayar la importancia del cumplimiento del mismo, para lo cual puede ser necesario recurrir a servicios de apoyo, servicios de salud mental o tratamiento de drogadicciones.

El abandono del consumo de tabaco y de drogas ilícitas y el uso de medidas de protección durante el coito pueden contribuir a reducir el riesgo de transmisión perinatal del VIH. El Servicio de Salud Pública de los EE.UU. recomienda que las mujeres infectadas no amamanten a sus hijos, aunque reciban TAR.

\section{RECOMENDACIONES SOBRE LA QUIMIOPROFILAXIS ANTIRRETROVÍRICA PARA REDUCIR LA TRANSMISIÓN PERINATAL DEL VIH}

Las recomendaciones que se presentan en el apartado siguiente están basadas en varias situaciones que se pueden encontrar frecuentemente en la práctica clínica, pero deben adaptarse a las circunstancias individuales de cada paciente. Los regímenes recomendados en la actualidad para el tratamiento de la madre (200 mg tres veces al día o $300 \mathrm{mg}$ dos veces al día) son distintos de los utiliza- 
dos en el estudio PACTG 076 (100 mg cinco veces al día) y podrían no tener la misma eficacia. Con estos nuevos regímenes es de esperar un mejor cumplimiento del tratamiento.

\section{SITUACIONES CLÍNICAS PARA EL USO DE ANTIRRETROVÍRICOS}

\section{Situación 1. Embarazadas infectadas por el VIH que nunca han recibido TAR}

Recomendación. Para reducir el riesgo de transmisión perinatal se recomienda el régimen quimioprofiláctico trifásico con ZDV en toda mujer infectada, independientemente de su carga vírica. $\mathrm{Si}$ su estado clínico, inmunológico o virológico lo requiere, se recomienda añadir otros antirretrovíricos al tratamiento anterior. Durante el primer trimestre se puede aplazar el inicio del tratamiento hasta después de las 10-12 semanas de gestación.

Comentarios. Se desconoce el mecanismo mediante el cual la ZDV reduce la transmisión perinatal, aunque es probable que la protección sea multifactorial. La ZDV cruza la placenta, requisito imprescindible para que el fármaco proteja al recién nacido. Como el paso transplacentario de otros antirretrovíricos es variable, al iniciar un TAR combinado durante el embarazo se debe incluir la ZDV siempre que sea posible. Si una paciente no recibe el componente antenatal del tratamiento quimioprofiláctico con ZDV, se sigue recomendando la administración de los componentes intraparto y neonatal.

Las decisiones con respecto al uso y a la elección de un régimen antirretrovírico deben ser individualizadas teniendo en cuenta: a) el riesgo de progresión de la enfermedad y los beneficios y riesgos del aplazamiento del inicio del tratamiento; b) el posible beneficio de la reducción de la carga vírica con respecto al riesgo de transmisión perinatal; c) la posible toxicidad de los fármacos y sus interacciones farmacológicas; d) la necesidad de un estricto cumplimiento del tratamiento con el fin de evitar la aparición de resistencia; e) el desconocimiento de los posibles efectos a largo plazo de la exposición intrauterina a los fármacos, y f) los datos preclínicos y clínicos conocidos sobre el uso de los antirretrovíricos durante el embarazo.

Cuando se administre un TAR combinado, el régimen debe ser elegido siguiendo las recomendaciones actuales para adultos no gestantes. El tratamiento con dos análogos de los nucleósidos sin añadirles un inhibidor de la proteasa o un inhibidor de la transcriptasa inversa no nucleósido no es reco- mendable debido al riesgo de supresión vírica insuficiente y de rápida aparición de resistencia. Si el TAR combinado se administra principalmente para reducir la transmisión perinatal, se puede considerar su interrupción después del parto. En tal caso se suspenderán todos los fármacos al mismo tiempo.

\section{Situación 2. Mujeres infectadas por el VIH con TAR durante el embarazo actual}

Recomendación. Si el embarazo se identifica después del primer trimestre, se debe seguir con el tratamiento. La ZDV debería formar parte del TAR antenatal, aunque esto no siempre es posible. Si el embarazo se identifica durante el primer trimestre, se debe proporcionar información acerca de los beneficios y de los posibles riesgos de la administración de antirretrovíricos durante el período organogénico. Si se opta por la interrupción del tratamiento durante el primer trimestre, se deben suspender todos los fármacos al mismo tiempo, con el fin de evitar la aparición de resistencia. Independientemente de cuál haya sido el régimen antenatal, se recomienda la administración de ZDV durante los períodos intraparto y neonatal. Las recomendaciones para la realización de pruebas de resistencia a los antirretrovíricos son las mismas que en pacientes no gestantes.

Comentarios. Si el tratamiento antenatal no ha incluido la ZDV, siempre que sea posible se debe seguir administrando ZDV i.v. durante el parto. Como la ZDV y la estavudina no se deben administrar conjuntamente debido al riesgo de antagonsimo farmacológico, las opciones en mujeres tratadas con estavudina oral en el período antenatal consisten en seguir con la estavudina oral sin ZDV i.v. durante el parto, o retirar la estavudina oral mientras se administra ZDV i.v. durante el parto. Además, el recién nacido debe recibir el tratamiento habitual con ZDV durante 6 semanas.

En mujeres que, pese al tratamiento, presenten una supresión subóptima de la carga vírica (> 1000 copias $/ \mathrm{mL}$ ) cerca del parto, no hay pruebas de que la administración de antirretrovíricos adicionales durante el parto proporcione una mayor protección frente a la transmisión perinatal. La influencia de la exposición previa a antirretrovíricos sobre la eficacia de la quimioprofilaxis con ZDV no está clara, y el hecho de que la paciente haya recibido tratamiento con ZDV antes del embarazo actual no debería alterar la recomendación de administrar quimioprofilaxis con ZDV para reducir la transmisión perinatal del VIH-1. 
Algunos médicos han recomendado la realización de pruebas de resistencia a los antirretrovíricos en todas las embarazadas, aunque esta medida es controvertida. La utilidad de estas pruebas, caras y de difícil interpretación, es mínima en embarazadas tratadas con antirretrovíricos y con buen control virológico. En la actualidad, solo se recomienda su realización en las mismas circunstancias que en pacientes no gestantes: infección aguda por VIH y fracaso virológico o supresión subóptima del virus tras el inicio del TAR. Aunque algunos médicos consideren la posibilidad de añadir otros antirretrovíricos a la ZDV en recién nacidos cuyas madres hayan recibido antes TAR, se desconoce la eficacia de esta medida.

\section{Situación 3. Mujeres de parto infectadas por el VIH que nunca han recibido TAR}

Recomendación. En esta situación existen varios regímenes eficaces: 1) dosis única de nevirapina al inicio del parto, seguida de la administración de una única dosis de nevirapina al recién nacido a las 48 horas de vida; 2) ZDV y lamivudina oral durante el parto, seguida de la administración oral de ZDV y lamivudina al recién nacido durante una semana; 3) ZDV i.v. intraparto seguida de la administración oral de ZDV al recién nacido durante 6 semanas, y 4) dos dosis de nevirapina más ZDV i.v. intraparto y 6 semanas de tratamiento del recién nacido con ZDV. Inmediatamente después del parto se deben efectuar recuentos de linfocitos CD4+ y determinaciones de la carga vírica para saber si la madre requiere TAR.

Comentarios. Aunque el TAR intraparto no previene la transmisión perinatal producida antes del parto, la mayoría de los casos de transmisión ocurren durante el parto o cerca del mismo, lo cual justifica la administración de alguno de los tratamientos mencionados. En la actualidad no hay datos que permitan determinar la eficacia relativa de estos regímenes en la prevención de la transmisión perinatal, con lo cual la elección de uno de ellos debe basarse en las circunstancias específicas de cada caso. El régimen de dos dosis de nevirapina tiene la ventaja de ser más barato y de más fácil y comprobable cumplimiento. No está demostrado que la combinación de los regímenes de dos dosis de nevirapina y ZDV i.v. intraparto más ZDV oral durante las 6 primeras semanas de vida proporcione más beneficios que los obtenidos solo con uno de ellos. Un posible beneficio de la combinación sería su potencial eficacia en mujeres infectadas por virus resistentes a la ZDV o a la nevirapina, aunque la transmisión perinatal de virus resistentes parece ser infrecuente.

\section{Situación 4. Recién nacidos cuyas madres no han recibido TAR durante el embarazo ni el parto}

Recomendación. Se le debe plantear a la madre la posibilidad de que el recién nacido reciba tratamiento neonatal con ZDV durante 6 semanas. El tratamiento debería comenzar cuanto antes, a ser posible en las 6 a 12 primeras horas de vida. Algunos médicos pueden optar por la combinación de la ZDV con otros antirretrovíricos, pero se desconoce la eficacia de esta estrategia en la prevención de la transmisión. Inmediatamente después del parto se deben efectuar recuentos de linfocitos CD4+ y determinaciones de la carga vírica para saber si la madre requiere TAR. Asimismo, el recién nacido debe ser sometido a pruebas diagnósticas para determinar si está infectado e iniciar el tratamiento lo antes posible.

Comentarios. No existen datos para determinar si la ZDV administrada únicamente durante el período neonatal reduce el riesgo de transmisión perinatal y tampoco está definido el intervalo en el que es posible obtener beneficios con la profilaxis postexposición. No obstante, hay datos que indican que el comienzo del tratamiento después de las 48 horas de vida es ineficaz.

\section{TRANSMISIÓN PERINATAL DEL VIH-1 Y VÍA DEL PARTO}

En embarazadas infectadas por el VIH, la conducta ante el parto debe estar dirigida a reducir el riesgo de transmisión perinatal y de complicaciones maternas y neonatales. Igual que con respecto al TAR, la decisión sobre la vía del parto compete a la mujer. Varios estudios han demostrado que la cesárea realizada antes del inicio del trabajo del parto y de la rotura de las membranas (cesárea electiva o programada) se asocia con una disminución significativa $(55-80 \%)$ de la transmisión perinatal del VIH-1 en comparación con otros tipos de parto, independientemente de la administración o no de ZDV.

Lo que todavía no se sabe es si la cesárea proporciona beneficios en caso de que la mujer esté recibiendo TAR combinado de gran actividad (TARGA) y presente una carga vírica baja o indetectable. Aunque no parece haber una carga vírica por debajo de la cual se pueda asegurar que no se producirá la transmisión, es improbable que la cesárea programada reduzca la baja tasa de transmisión ob- 
servada en las mujeres tratadas con carga vírica indetectable ni prevenga la transmisión in utero. El American College of Obstetrics and Gynecology (ACOG) ha elegido el valor de 1000 copias/mL como el umbral por encima del cual recomienda la cesárea como complemento en la prevención de la transmisión.

En mujeres no infectadas por el VIH, la morbilidad y mortalidad maternas son mayores tras la cesárea que tras el parto vaginal. Las complicaciones tras la cesárea programada son más frecuentes que tras el parto vaginal, pero menos frecuentes que tras la cesárea urgente. Entre los factores que aumentan el riesgo de complicaciones postoperatorias se encuentra el bajo nivel socioeconómico, las infecciones genitales, la obesidad o la malnutrición, el tabaquismo y el parto prolongado o la rotura de las membranas. Las complicaciones de la cesárea en mujeres infectadas por el VIH son similares en frecuencia y magnitud a las descritas en mujeres no infectadas.

Si se toma la decisión de realizar una cesárea programada para prevenir la transmisión del VIH, el ACOG recomienda que se haga a las 38 semanas de gestación.

El tratamiento con ZDV i.v. debe comenzar 3 horas antes de la cesárea programada. No se deben suspender otros antirretrovíricos cerca del momento del parto, cualquiera que sea la vía del mismo. Como la morbilidad infecciosa materna puede estar aumentada, se puede administrar profilaxis antimicrobiana perioperatoria, aunque no hay datos controlados y específicos sobre su eficacia en mujeres infectadas por el VIH sometidas a cesárea programada.

En cuanto al parto vaginal, la duración de la rotura de las membranas es un factor de riesgo demostrado de transmisión perinatal en mujeres no tratadas con antirretrovíricos. En las tratadas con ZDV, los datos existentes son contradictorios. Lo mismo ocurre con los procedimientos obstétricos que aumentan el riesgo de exposición del feto a la sangre materna, como la amniocentesis; no obstante, se recomienda evitarlos.

\section{Recomendaciones}

- Con el TARGA es de esperar una reducción tanto de la carga vírica como de la tasa de transmisión vertical. Para reducir la transmisión perinatal del VIH se recomienda, como mínimo, la profilaxis con ZDV según el régimen del estudio PACTG 076.

- Durante el embarazo, la carga vírica plasmática debe ser monitorizada como en cualquier adulto infectado por el VIH. Para aconsejar a la mujer acerca de la vía del parto se debe utilizar la determinación más reciente.
- La transmisión perinatal del VIH-1 disminuye con la cesárea programada en mujeres no tratadas con antirretrovíricos o sometidas a profilaxis con ZDV y carga vírica desconocida; sobre los casos con baja carga vírica plasmática no hay datos concluyentes.

- Las mujeres con carga vírica > 1000 copias/mL deben ser informadas de los beneficios de la cesárea en lo que se refiere a la reducción del riesgo de transmisión vertical. Aunque no hay datos concluyentes, en mujeres con carga vírica < 1000 copias/mL tratadas con antirretrovíricos es improbable que la cesárea aporte beneficios adicionales.

- La mujer debe ser informada de los riesgos de la cesárea, que deben ser ponderados frente a los potenciales beneficios para el recién nacido.

\section{SITUACIONES CLÍNICAS RELACIONADAS CON LA VÍA DEL PARTO}

\section{Situación A}

Mujer con infección conocida que se presenta hacia el final del embarazo (alrededor de las 36 semanas de gestación), que no está recibiendo antirretrovíricos y en la que es improbable que se obtengan datos sobre la carga vírica y el recuento de linfocitos antes del parto.

Recomendación. Se debe iniciar el TAR, al menos con ZDV, e informar a la paciente de que la cesárea probablemente reduzca el riesgo de transmisión vertical. Asimismo, se le debe informar de los riesgos que para ella puede suponer la cesárea. Si opta por la cesárea, esta debe ser programada para las 38 semanas de gestación; al menos 3 horas antes se debe iniciar la infusión i.v. continua de ZDV y el recién nacido debe recibir ZDV oral durante las primeras 6 semanas de vida. En cuanto se disponga de los resultados del recuento de linfocitos y de la carga vírica se debe analizar la necesidad de comenzar o seguir con el TAR combinado.

Comentario. En ausencia de tratamiento, es improbable que la carga vírica sea $<1000$ copias $/ \mathrm{mL}$. Aunque se iniciara inmediatamente un tratamiento combinado, la reducción de la carga vírica a niveles indetectables tardaría varias semanas.

\section{Situación B}

Mujer infectada cuya atención prenatal ha comenzado al principio del tercer trimestre, que 
está recibiendo TARGA y que presenta una respuesta virológica inicial, pero cuya carga vírica sigue siendo considerablemente $>1000$ copias $/ \mathrm{mL}$ a las 36 semanas de gestación.

Recomendación. Se debe seguir con el TAR combinado actual si la carga vírica está disminuyendo como se esperaba, pero la paciente debe ser informada de que es improbable que antes del parto sea $<1000$ copias $/ \mathrm{mL}$. Por consiguiente, la cesárea programada puede contribuir a evitar la transmisión intraparto. Asimismo, se le debe informar de los riesgos que para ella puede suponer la cesárea. Si opta por la cesárea, esta debe ser programada para las 38 semanas de gestación; al menos 3 horas antes se debe iniciar la infusión i.v. continua de ZDV y el recién nacido debe recibir ZDV oral durante las primeras 6 semanas de vida. Se debe seguir con las demás medicaciones antirretrovíricas todo el tiempo que sea posible, tanto antes como después de la cesárea.

Comentario. Los datos existentes indican que, en mujeres tratadas con $\mathrm{ZDV}$, la tasa de transmisión vertical es del 1 al 12\% (media de 5,7\%) cuando la carga vírica es de 1000 a 10000 copias/mL, y del 9 al 29\% (media de 12,6\%) cuando es > 10000 copias $/ \mathrm{mL}$, y que estas cifras disminuyen con la cesárea programada. Independientemente de la vía del parto, la madre debe recibir ZDV i.v. durante el parto, y el recién nacido, ZDV oral durante 6 semanas. En caso de que haya que interrumpir temporalmente la administración de otros antirretrovíricos, se deben suspender todos al mismo tiempo y reiniciarlos también simultáneamente, con el fin de reducir la posibilidad de que se cree resistencia.

\section{Situación C}

Mujer infectada que está recibiendo TARGA y presenta carga vírica indetectable a las 36 semanas de gestación.

Recomendación. La mujer debe ser informada de que su riesgo de transmisión perinatal es bajo (probablemente $\leq 2 \%$ ), aunque el parto tenga lugar por vía vaginal, y de que no hay información suficiente para determinar si una cesárea programada podría reducir aún más dicho riesgo.

Comentario. Aunque la cesárea proporcionara una reducción adicional del riesgo, esta sería pe- queña y debería sopesarse frente a los riesgos de la cesárea. De cualquier forma, si la mujer opta por la cesárea, debe respetarse su decisión. Si opta por el parto vaginal, se debe reducir al mínimo posible la duración de la rotura de las membranas. Se deben evitar medidas que pueden aumentar el riesgo de transmisión, como la colocación de electrodos en el cuero cabelludo fetal o el parto instrumental (fórceps o ventosas). Independientemente de la vía del parto, la madre debe recibir ZDV i.v. durante el parto, y el recién nacido, ZDV oral durante 6 semanas. En caso de que haya que interrumpir temporalmente la administración de otros antirretrovíricos, se deben suspender todos al mismo tiempo y reiniciarlos también simultáneamente, con el fin de reducir la posibilidad de que se cree resistencia.

\section{Situación D}

Mujer infectada que ha optado por la cesárea programada, pero que se presenta al principio del trabajo del parto o poco después de la rotura de las membranas.

Recomendación. Se debe comenzar inmediatamente la administración i.v. de ZDV, dado que la mujer está de parto o tiene las membranas rotas. Si el parto está progresando rápidamente, se debe dejar que tenga lugar por vía vaginal. En caso contrario, unos optan por administrar la dosis inicial de ZDV y proceder a la cesárea, y otros por la administración de oxitocina. Si el parto tiene lugar por vía vaginal, se deben evitar medidas como la colocación de electrodos en el cuero cabelludo fetal o el parto instrumental (fórceps o ventosas). El recién nacido debe recibir ZDV oral durante 6 semanas.

Comentario. No hay datos para saber si la cesárea poco después de la rotura de las membranas reduce el riesgo de transmisión vertical. La probabilidad de que así sea disminuye a medida que aumenta la duración de la rotura de las membranas.

\section{RECOMENDACIONES PARA LA MONITORIZACIÓN DE LA MADRE Y DEL RECIÉN NACIDO}

\section{Embarazada y feto}

Las embarazadas infectadas por el VIH-1 deben ser monitorizadas como cualquier paciente no gestante, con determinaciones del recuento de linfocitos CD4+ y de la carga vírica cada tres a cua- 
tro meses. Los resultados determinarán la necesidad de TAR para la madre, la necesidad de alterarlo o la necesidad de iniciar la profilaxis frente a la neumonía por Pneumocystis carinii. Los cambios del recuento absoluto de linfocitos CD4+ pueden deberse más a los cambios fisiológicos del embarazo que a un efecto de la gestación sobre la enfermedad; el porcentaje de linfocitos CD4+ es más estable y puede reflejar mejor el estado inmunitario del embarazo. En cuanto a las posibles complicaciones del TAR, se recomienda la realización periódica de pruebas hematológicas y determinaciones de las enzimas hepáticas en pacientes tratadas con ZDV, y determinaciones de la glucemia en pacientes tratadas con inhibidores de la proteasa. La monitorización fetal anteparto en mujeres tratadas únicamente con quimioprofilaxis con ZDV debe basarse en las indicaciones clínicas habituales, dado que no hay pruebas de que la ZDV incremente el riesgo de complicaciones fetales. En mujeres sometidas a TAR combinado puede ser necesaria una monitorización más intensiva.

\section{Recién nacido}

Antes de la administración de ZDV se debe realizar un hemograma completo. La anemia es la principal complicación del tratamiento neonatal, por lo cual se debe realizar una determinación de la hemoglobinemia al final de las 6 semanas de tratamiento, y repetirla a las 12 semanas. Los recién nacidos que ya están anémicos al nacer, los prematuros y los hijos de mujeres sometidas a TAR combinado necesitan una monitorización más intensiva. Todos los recién nacidos de mujeres infectadas por el VIH deberían empezar a recibir profilaxis frente a la neumonía por $P$. carinii después de las 6 semanas, al acabar la profilaxis con ZDV. Los recién nacidos con pruebas virológicas negativas durante las primeras 6 semanas de vida deben ser sometidos a nuevas pruebas diagnósticas tras la conclusión del régimen profiláctico antirretrovírico neonatal.

\section{Seguimiento de la mujer tras el parto}

Las pacientes infectadas por el VIH-1 necesitan tras el parto una atención integral y servicios de apoyo, cuyos componentes incluyen:

- Atención primaria, obstétrica, pediátrica y especializada en la infección por VIH

- Servicios de planificación familiar

- Servicios de salud mental
- Tratamiento de drogadicciones

- Coordinación de la atención a la mujer, a sus hijos y a otros familiares

Un tema preocupante es el cumplimiento del TAR tras el parto, que puede necesitar apoyo adicional.

\section{Seguimiento a largo plazo del recién nacido}

No hay datos suficientes para evaluar el efecto de la exposición intrauterina a la ZDV, y todavía menos a otros antirretrovíricos, sobre el riesgo a largo plazo de toxicidad y neoplasias. Los datos del estudio PACTG 076 no muestran diferencias entre los niños expuestos a la ZDV y los no expuestos en lo que se refiere a los parámetros inmunológicos, neurológicos y del crecimiento hasta los 6 años de edad. Tampoco se han observado neoplasias malignas. Se siguen reuniendo datos acerca de estos posibles problemas y la observación de estos niños debería seguir hasta la edad adulta.

\section{ASPECTOS QUE NECESITAN SER MEJOR INVESTIGADOS}

\section{Seguridad y farmacocinética de los antirretrovíricos}

Aunque el número de fármacos antirretrovíricos está aumentando rápidamente, son pocos los que se han estudiado en el embarazo. Los datos actuales acerca de la seguridad y farmacocinética de los antirretrovíricos en las embarazadas y los recién nacidos son insuficientes, especialmente en lo que se refiere a los regímenes combinados. Entre los aspectos que merecen mayor atención se encuentran la disfunción mitocondrial, la toxicidad hepática y hemática, la resistencia y los efectos adversos sobre el desenlace del embarazo. También son necesarios más datos acerca de los efectos sobre la carga vírica en diferentes compartimientos corporales, como el plasma o las secreciones genitales, y su influencia sobre el riesgo de transmisión perinatal.

\section{Resistencia a los fármacos}

La administración aislada de ZDV para la profilaxis de la transmisión perinatal puede aumentar la incidencia de mutaciones de resistencia a la ZDV en mujeres cuya replicación vírica no ha sido suprimida al máximo. En estas pacientes, la administra- 
ción de fármacos frente a los cuales se puede adquirir resistencia genotípica por una única mutación, como la nevirapina o la lamivudina, puede conducir a la aparición de virus con resistencia genotípica en una importante proporción de casos.

\section{Adherencia al tratamiento}

La complejidad de los regímenes combinados dificulta el cumplimiento del tratamiento. Son necesarias medidas innovadoras para mejorar la adherencia al tratamiento durante el embarazo y después del mismo, y para asegurar que los recién nacidos reciben la profilaxis con ZDV.

\section{Papel de la cesárea en mujeres con carga vírica indetectable o corta duración de la rotura de las membranas}

Son necesarios nuevos estudios para determinar si la cesárea también proporciona beneficios clínicamente significativos en mujeres tratadas con antirretrovíricos y carga vírica baja o indetectable y en mujeres con rotura de las membranas de muy corta duración.

\section{SYNOPSIS}

\section{Recommendations on the use of antiretroviral agents in pregnant women infected with HIV-1}

In February 1994, a clinical trial by the Pediatrics AIDS Clinical Trials Group (PACTG 076) demonstrated, for the first time, that it was possible to reduce the risk of vertical transmission of human immunodeficiency virus type 1 (HIV-1) by nearly $70 \%$ by means of a triple therapeutic regimen: 1) oral zidovudine ( $Z D V)$ beginning anytime between the 14th and 34th week of gestation until the end of pregnancy; 2) intravenous $Z D V$ during pregnancy, and 3) administration of oral ZDV to neonates during the first 6 weeks of life. Later, epidemiologic studies performed in the United States of America and France showed that this regimen drastically reduced perinatal transmission in clinical practice. Since then, important strides have been made, not only in terms of treatment (new drugs and highly effective therapeutic regimens) and diagnosis (tests that can measure the viral load), but also in terms of an increased understanding of the pathogenesis of perinatal transmission of HIV-1.

This report contains: a) a review of special considerations to be kept in mind when administering antiretroviral agents to pregnant women; $b$ ) a current overview of the results of clinical and epidemiologic trials dealing with the prevention of perinatal transmission of $H I V-1$; c) a look at the use of tests for measuring HIV-1 RNA (viral load) during preg$n a n c y ; d)$ the most recent recommendations on the use of antiretroviral chemoprophylaxis and elective cesarean section for reducing perinatal viral transmission. These recommendations apply to the United States, and other countries may prefer to use different approaches. 